\title{
Educação, telenovela e crítica
}

Maria Lourdes Motter

Professora livre-docente do Departamento de Comunicações e Artes da ECA/USP. Coordenadora do NP Ficção Seriada Televisiva da Intercom $^{1}$.

E-mail: lumotter@ig.com.br

Quais seriam os fatores capazes de justificar a omissão da escola com relação ao gênero, sabendo-se que afeta não só a expressiva parcela da população brasileira que assiste a telenovelas, mas atinge indiretamente todos os outros segmentos, uma vez que mecanismos de repercussão a difundem para toda a sociedade? Queremos com isso dizer que ela entra na composição da cultura nacional. Ignorá-la, quando se objetiva trabalhar a comunicação e a cultura, equivale a fugir não de uma ficção sem nobreza para entrar no espaço da educação formal, porém ignorar um elemento, um componente significativo na constituição da própria realidade.

Descobri-la como espaço educativo é o grande desafio. Espaço que deve ser construído pelos educadores através da análise e crítica do produto. Como realizar essa tarefa? Que instrumentos utilizar? Como recolher amostras com que se possam trabalhar? A quem cabe essa tarefa? Quando realizá-la? Será que o investimento vale a pena? As perguntas são muitas e poderiam prosseguir indefinidamente.

As razões para manter a telenovela fora da sala de aula são diversas: argumentos dos órgãos superiores de ensino, dos órgãos mais próximos a que está submetida a escola, da direção, dos pais, dos professores, enfim, da sociedade. Com certeza, o único segmento que não terá argumentos contra a telenovela será aquele representado pelos alunos. Porque assistem, gostam, comentam e nela encontram seus momentos diários de ficção. Lá, sempre pontualmente, a um simples acionar de botões, está o contador de histórias fazendo avançar uma narrativa dramatizada, com personagens conhecidas, vivenciando seus conflitos, domesticando circunstâncias hostis, driblando os azares da sorte na luta tenaz pela consecução de seus objetivos.

Sabemos da dificuldade de acesso a livros e jornais da maioria da população brasileira, excluída da cultura impressa, como dos bens de consumo em geral. Não será essa uma realidade da maior parte dos estudantes brasileiros? Será que não é o caso de tirar o máximo proveito dos bens a que eles têm acesso? E o bem mais visível na nossa sociedade não é a televisão? E o que se extrai da televisão, quando acontece ser levada em conta? Os produtos tidos como os de maior prestígio: o telejornal. Qualquer um? Não. O mais prestigiado, o mais nobre. Escolhido a dedo, em função do horário, da emissora, do entorno

1. Intercom - Sociedade Brasileira de Estudos Interdisciplinares da Comunicação. 
2. Ver sobre $\mathrm{o}$ assunto HELLER, Agnes. O cotidiano e a história. Rio de Janeiro: Paz e Terra, 1985. LEFEBVRE, H. A vida cotidiana no mundo moderno. São Paulo: Ática, 1991.

3. Ver BOURDIEU, P. Sobre a televisão. Rio de Janeiro: Jorge Zahar Editor, 1998, e Contrafogos: táticas para enfrentar a invasão neoliberal. Rio de Janeiro: Jorge Zahar Editor, 1997. cenográfico etc. A visão que permanece quanto ao conceito de cultura em nossa tradição é a que a cinde em duas, uma do povo e outra dos letrados.

Dito desse modo, parece que estamos falando da Idade Média, mas a intenção é trazer para o presente o quanto de superado existe nessa visão em que cultura se confunde com música clássica, filmes de arte, teatro dos gregos ou de monstros sagrados e que, ironicamente, foram populares em sua época.

Nada há de origem mais popular do que a ópera italiana. São as formas que distinguem o popular do erudito? Será que a perenidade de algumas obras tem a ver com a forma ou com a universalidade atemporal do conteúdo humano que ela carrega? Classificar o mundo por formas não seria um modo fácil de mapeá-lo, de domesticar rebeldias, de misturar conteúdos, de embaralhar as cartas para confundir o jogador ingênuo? Para desqualificá-lo, tornando-o dócil à manipulação?

Não temos a pretensão de poder conseguir responder a estas perguntas. As respostas são importantes, mas persegui-las é o único modo possível de andar rumo ao conhecimento, um conhecimento que de abstrato só tem o ato de pensar enquanto atividade não exteriorizada, pois nosso objetivo último e permanente é compreender a concretude do real no qual estamos mergulhados.

Entre os indicadores de rejeição e de desqualificação da telenovela, ver estereótipos em tudo se converte em uma forma dissimulada de estereotipia. No cotidiano ${ }^{2}$ governado pela fé e pela confiança, o estereótipo é um poderoso agente a serviço do engano para aqueles que se transformaram em caçadores de estereótipo. Confundem-se modelos, estruturas, modos de compor a realidade, bem como características próprias do gênero com generalização do que é válido apenas para um fazer específico. No âmbito da indústria cultural a crítica fácil busca, através de esquemas de análise incorporados, falar de tudo em geral, sem conhecimento suficiente para dar conta dos produtos particulares. Se há muito se firmou a necessidade de trabalhar o paradoxo de repetir e inovar dessa modalidade de cultura produzida industrialmente, não se admite que se desconsidere a dialética aí implicada. Nesse sentido, trabalhar o tempo todo com base na idéia de reprodução é tão indutor de erro como aceitar que a indústria cultural funda a inovação como característica maior de seus produtos.

Como se pode observar, a imprensa, enquanto formadora de opinião, define uma posição e irradia para a sociedade determinado modo de ver a telenovela que inibe, senão silencia ou inviabiliza, opiniões divergentes. Temse aí o que podemos classificar como discurso autoritário, na medida em que as críticas tendentes a avaliar aspectos positivos da telenovela são apagadas, dando a conhecer apenas a crítica desqualificadora hegemônica. Lembramos as observações de Pierre Bourdieu ${ }^{3}$ sobre a conivência dos meios e a tendência de se protegerem enquanto meios de comunicação. Isto porque a crítica não age contra a audiência para competir com a televisão, antes a legitima como meio, ao difundi-la e realimentá-la com a tematização dos assuntos que lhe dizem respeito. Também vive dela - seu nutriente - a ponto de poder ser 
considerada um subproduto daquela. Tampouco interfere significativamente na audiência, pois estimula o ver televisão. Apenas e tão-somente propõe seu modo de ler num viés desprestigiador do seu produto maior: a telenovela. Desse modo, orienta-se para que se a veja como mero entretenimento que não se deve levar a sério, na medida em que não acrescenta nada e às vezes pode fazer mal.

Todavia, o controle sobre a opinião se exerce no sentido do laissez-faire, ou seja, fazer a crítica que mantenha as coisas tal como estão. Essa posição gera desprezo ou indiferença, impedindo uma ação cidadã por parte dos telespectadores, que deveriam ratificar e estimular as boas propostas, aumentar seu nível de exigência e cobrar um controle de qualidade sempre crescente. Não pretendemos responsabilizar a crítica pela oscilação da qualidade das telenovelas. Queremos apenas discutir sua contribuição para a permanência do descompromisso das partes envolvidas: produção e audiência.

Falar indistintamente em telespectador e audiência, como entidades vagas e abstratas, não esgota o estoque de conseqüências para um setor específico: a escola. Vítima e vilã, ela responde pela tarefa de formar as novas gerações, num contexto de despreparo dos que ensinam, das privações que cercam a instituição, envolvendo problemas de tantas e diversas ordens que seria impossível elencá-las.

As pesquisas mostram a TV, e sobretudo a telenovela, fora da sala de aula. Se há muitas razões para isso, uma delas, com certeza, é a falta de legitimidade. Como veículo destinado ao entretenimento prioritariamente, ela se distancia das questões sérias tratadas como conteúdos das disciplinas, numa visão de ensino que se cristalizou no tempo e enrijecida recebe os sopros e aragens de mudança. Agora, o trabalho é de erosão. E isso só se faz no tempo.

Assim, pelo controle exercido sobre a opinião, a crítica de TV assume, do ponto de vista de sua responsabilidade social, uma postura ideológica que reitera a tendência de simplificação própria da vida cotidiana, deforma conteúdos propondo um saber que na realidade resulta em não-saber, na medida em que oblitera as possibilidades de uma percepção mais em consonância com o real da telenovela. Esta, por sua vez, com freqüência, tem apresentado propostas de compreensão da realidade que constituem modos de inteligibilidade do nosso social concreto.

Consideramos seja tempo de essas publicações olharem para si próprias e entenderem que mais que alimentar um mercado é preciso ver a realidade que esta palavra encobre. Afinal, o mercado é constituído de consumidores, que são indivíduos, cidadãos a quem se deve respeitar. A nosso ver o respeito implica, no tocante às publicações e à crítica, que se assuma o caráter indissociável do par comunicação-educação, com a implícita reciprocidade de propósitos. $\mathrm{O}$ compromisso com o educar (de modo não-formal) é inerente (ao) e independe do campo de conhecimento em que esteja inserido o veículo ou a crítica.

Embora a função mais visível da telenovela seja a de proporcionar distração, a isto ela não se limita e é evidente seu propósito de educar. Se não por 
4. O CARTEIRO e o poe-

ta (II Postino). Direção:

Michael Radford. Itália,

1994 (109 min.). Concorreu ao Oscar em 1997 e

foi premiado por melhor trilha sonora.

5. Ver MOTTER, M. L. O Carteiro e o Poeta: a força da poesia. Comunicação \& Educação, São Paulo: CCA-ECA-USP/Moderna, n. 8, jan./abr. 1997. intenção do meio, pela integridade de certos autores que contam histórias porque têm algo a dizer. Dizer num sentido que se pode entender como mostrar, fazer ver, interferir.

Seria mesmo um desperdício usar a grande tribuna para não propor nada. Só um tolo, indigno do nome de autor e de ocupar tal espaço seria capaz de preenchê-lo por apreço apenas à fama e ao régio pagamento que recebe. Infelizmente isso acontece quando falta talento para compreender, rearticular e tornar compreensível um mundo que só deve ir bem para ele e seu entorno. Como afirmou várias vezes Dias Gomes, indignado, "quem não vem ao mundo para incomodar, não devia vir ao mundo”. Está claro que incomodar tem exatamente o sentido de denunciar, fazer ver, fazer compreender para interferir e mudar. Afinal, conviver com problemas passa a ser para o mundo do senso comum, que não divisa outro horizonte além do presente, o habitual, o comum, o rotineiro, o cotidiano.

Tal qual no filme $O$ carteiro $e$ o poeta $a^{4}$ em que a população da Ilha Negra acostuma-se à falta de água e considera isso uma coisa normal. Nem sequer lhes ocorre tratar-se de uma situação absurda, de solução possível. A convivência, a familiaridade, incorporou o que deveria manter-se como problema em uma característica da vida local. Assim naturalizada, deixou de ser um problema. E, não havendo problema, nada mais há a fazer. No filme, como se sabe, o carteiro irá mudar essa situação e outras na Ilha, graças à convivência freqüente com o poeta Pablo Neruda, ele mesmo um exilado que incomodava em seu país, com quem aprendeu que o homem só adquire a qualidade humana se for capaz de transformar ${ }^{5}$.

\section{ARTIGOS NACIONAIS}

Este número da revista traz artigos nacionais ligados ao jornalismo televisivo, à música como produto marcadamente industrializado e ao pouco explorado domínio dos videogames.

Marco Schneider, em A teoria do valor de Marx e a educação do gosto, recupera elementos da teoria marxista para demonstrar como a tradição autoritária da educação formal reproduz e reafirma a cisão entre o prazer e o conhecimento, processo maniqueísta reforçado pela indústria cultural. Mayra Rodrigues Gomes, em Perfis: modos de inserção de jornais televisivos, examina o delineamento dos espaços no telejornalismo enquanto dimensão propícia à instalação de dispositivos disciplinares que organizam o campo do que deve ser visto, do que deve ser objeto de atenção.

Por sua vez, Fabiano Andrade Curi, em Uma proposta para a leitura crítica dos videogames, analisa o consumo e discute as possibilidades do uso de videogames em ambientes educacionais como fonte de discussão para algumas disciplinas. Walter de Sousa Júnior, com Apropriações melodramáticas: o caso Pedrinho no Jornal Nacional e em Senhora do Destino, elabora o estudo das trocas que se efetuam entre a telenovela e o telejornal e recupera elementos do melodrama na construção 
jornalística que apontam a mistura de gêneros como recurso para captura da audiência.

\section{ARTIGO INTERNACIONAL}

Sarah Corona Berkin relata em $\mathrm{O}$ estudo das formas comunicativas como disciplinas do corpo: o caso da fotografia huichol os resultados de sua pesquisa em uma comunidade indígena mexicana sem acesso a imagens mediáticas, e toma a fotografia como lugar de interseção do olhar individual e coletivo dos índios huicholes para identificar, com base no que o sujeito fotografa, as competências que o configuram.

\section{GESTÃO DA COMUNICAÇÃO}

Luciano Somenzari, em A luta contra o desemprego: os portões de fogo da atualidade, discute a questão do desemprego e busca realizar uma proposta de comunicação que contribua para a maior eficiência da Central de Trabalho e Renda, agência pública que atua a partir da premissa de que não há emprego suficiente para todos.

\section{ENTREVISTA}

O entrevistado deste número é o artista gráfico Elifas Andreato, com quem Roseli Fígaro dialoga resgatando a trajetória de seus passos iniciais como desenhista, sua evolução artística e orientação política até o reconhecimento e consagração de sua arte.

\section{CRÍTICA}

Em Uma propaganda exemplar do governo Lula, João Anzanello Carrascoza comenta a falta de crítica ao conteúdo das campanhas publicitárias do governo e demonstra a utilização distorcida e passadista de referências culturais com a análise do comercial "ProUni - Universidade para Todos".

\section{DEPOIMENTO}

Marília Franco traz um importante resgate do processo de implantação das TVs universitárias, seus desafios e possibilidades pedagógicas, pautado em sua vivência no espaço da TV USP. Destaca a importância da televisão no Brasil e a carência de pesquisa científica sobre seu papel histórico. Nesta seção, o leitor encontrará o cruzamento entre as diferentes propostas de TV e a intenção, levada a efeito com profundo compromisso, de fazer da TV USP um espaço de experimentação profissional vinculado à produção de conhecimento. 


\section{EXPERIÊNCIA}

Maria Cristina Castilho Costa expõe sua experiência com a educação a distância no curso de especialização lato sensu Gestão da Comunicação da ECAUSP. No relato são apresentadas as peculiaridades, vantagens e desvantagens do trabalho on-line combinado com a educação presencial. Nesta seção, o leitor encontrará uma visão crítica sobre o assunto e uma valiosa contribuição para a construção de caminhos alternativos na educação.

\section{POESIA}

Manuel Bandeira (1886-1968) figurou entre os principais nomes que fizeram a vanguarda literária modernista no Brasil. Foi professor, escreveu para jornais, atuou como crítico de artes plásticas e tornou-se membro da Academia Brasileira de Letras em 1940. Apesar da saúde delicada e da tuberculose, que o obrigou a passar grande parte de sua vida em clínicas de saúde e influenciou diretamente sua obra poética, ele viveu até os 82 anos. Da vasta e consagrada obra que deixou, destacam-se: A Cinza das Horas, Carnaval, O Ritmo Dissoluto, Libertinagem, Lira dos Cinqüent'Anos, entre outras. Nesta seção, o leitor terá uma pequena amostra dos poemas que marcaram época e que ajudaram a desenvolver o gosto poético de várias gerações.

\section{SERVIÇOS}

O Projeto Clicar, em funcionamento na Estação Ciência, atende crianças e adolescentes entre 6 e 17 anos que se encontram em situação de risco pessoal e social. O espaço educativo integrado dispõe de biblioteca, computadores com acesso à internet e diversos materiais para as atividades educativas e recreativas. Também são realizadas sessões de cinema, passeios a exposições e museus, além de trabalhos cotidianos, como a elaboração de revista e jornal eletrônicos e manutenção do website, e muito mais. Não é necessário efetuar matrícula e a participação deve ser espontânea.

\section{VIDEOGRAFIA}

Maria Ignês Carlos Magno mostra como o olhar e o pensamento não são neutros, bem como os olhares dos autores e dos narradores, optando assim por elaborar as atividades de sua seção através dos filmes Narradores de Javé, de Eliane Caffé, e Um filme falado, de Manoel de Oliveira, tendo suas narrativas como foco. A tentativa é mostrar os diálogos existentes entre diferentes narrativas; as confluências entre a narrativa cinematográfica e as estruturas das narrativas literárias; as possibilidades de pensar sobre as línguas e sobre as escritas que falam e escrevem as histórias e as prosas do mundo. 


\section{BOLETIM BIBLIOGRÁFICO}

As subseções Bibliografia sobre telenovela e Bibliografia sobre comunicação e educação trazem livros, teses e dissertações relativos às respectivas temáticas. Endereços úteis na internet podem contribuir para incrementar as tarefas cotidianas dos professores.

\section{ATIVIDADES EM SALA DE AULA}

Ruth Ribas Itacarambi propõe projetos pedagógicos a serem desenvolvidos em sala de aula com alunos do ensino fundamental e médio, utilizando-se dos artigos publicados neste número. As três atividades têm como propósito apresentar sugestões para discutir as novas formas de ensino e aprendizagem, promovendo a interação entre as diferentes áreas do conhecimento na perspectiva da sociedade atual.

Resumo: A autora propõe questionamentos sobre os fatores capazes de justificar a omissão da escola com relação ao gênero telenovela, sabendo-se que afeta não só a expressiva parcela da população brasileira que a assiste, mas atinge indiretamente todos os outros segmentos, uma vez que mecanismos de repercussão a difundem para toda a sociedade. Observa que ignorá-la, quando se objetiva trabalhar a comunicação e a cultura, equivale a fugir não de uma ficção sem nobreza para entrar no espaço da educação formal, porém desprezar um elemento, um componente significativo na constituição da própria realidade. Avalia que descobri-la como espaço educativo é o grande desafio. Espaço que deve ser construído pelos educadores através da análise e crítica do produto.

Palavras-chave: gênero, telenovela, comunicação e cultura, ficção seriada, estereótipos, cotidiano e linguagem.
Abstract: The author proposes factors to explain the school omission related to the gender issue, which affects not only the expressive part of the Brazilian population that watches to soap operas, but also other segments, once that the repercussion engines spread it to all society. She observes that to ignore it, when the objective is to work with communication and culture, is not digressing of a fiction without nobility to enter the formal education, but ignoring a significant component of the reality. She appraises that discovering the gender issue as educational space is the great challenge. A space that must be built by educators through the critical analysis of the product.

Keywords: gender, brazilian soap opera, communication and culture, serial fiction, stereotypes, quotidian and language. 